\title{
Retrospective Analysis of Early Impact of COVID-19 on Systemic Cancer Treatment-A Pilot Study
}

\author{
Anakha Pattiyeil $^{1}$ Febin Antony ${ }^{2} \quad$ Sunu L Cyriac ${ }^{1, \odot} \quad$ Anilkumar Jose $^{1} \quad$ Jini M P ${ }^{3}$ \\ ${ }^{1}$ Department of Medical Oncology and Haematology, Amala \\ Institute of Medical Sciences, Thrissur, Kerala, India \\ ${ }^{2}$ Department of Radiation Oncology, Amala Institute of Medical \\ Sciences, Thrissur, Kerala, India \\ ${ }^{3}$ Department of Biostatistics, Amala Institute of Medical Sciences, \\ Thrissur, Kerala, India \\ Ind J Med Paediatr Oncol 2021;42:15-20. \\ Address for correspondence Sunu Lazar Cyriac, MD, DM, \\ Department of Medical Oncology and Haematology, Amala Institute \\ of Medical Sciences, Thrissur, Kerala 680555, India \\ (e-mail: drsunucyriac@gmail.com).
}

\begin{abstract}
Keywords

- COVID-19

- cancer care

- lockdown

- pre-COVID phase

- pandemic

- early impact
\end{abstract}

\section{Introduction}

The COVID-19, which began as an epidemic in Wuhan, China, was declared as a global pandemic $^{1}$ by the World Health Organization (WHO) in March 2020. ${ }^{2}$ According to the WHO COVID dashboard, there were a total of 6,264 confirmed cases and 5,904 deaths by

DOI https://doi.org/ $10.1055 / \mathrm{s}-0041-1730239$ ISSN 0971-5851
April 30, 2020. The numbers increased to 53,766,728 and 1,308,975 in November 15, 2020. ${ }^{3}$ Cancer patients infected with COVID-19 are at 3.5 times higher risk of developing complications, compared with the general population. ${ }^{4}$ This study compares the pre-COVID phase (PCP) and post lockdown relaxation phase (PLRP) cancer care changes in a tertiary care center in India. 


\section{Materials and Methods}

This was a comparative descriptive study. The aim of the study was to understand the impact of the nationwide lockdown on systemic cancer care. The primary objective was to compare the major changes in the patient care metrics with special emphasis on new patient registrations, pre-booking, inpatient occupancy, day care chemotherapy, before and after the lockdown in the fight against COVID-19. And the secondary objective was to identify the group of patients who had the major impact during the study period based on their demographic factors, disease-related, and hospital visit-related parameters. Sample size calculation was done based on testing the difference of proportion of PCP and PLRP with allocation ratio 2:1. Based on this, total sample size calculated was 672 among which 448 in PCP and 224 in PLRP. The calculated sample size for the Institutional Ethics Committee approval was obtained prior to the study (Ref. No:10/IEC/20/AIMS-16 on 13-07-2020). Data from PCP was compared with PLRP. PCP was from January 15th to 30th 2020, the time being just before the first proven case of COVID-19 in India. PLRP was from April 15th to 30th, 2020. This corresponded to the time period when the nationwide lockdown for containing COVID-19 was relaxed for the first time. ${ }^{5,6}$ The study was conducted in the Department of Medical Oncology and Haematology (DMOH) of our hospital. Patients who presented to the two units of $\mathrm{DMOH}$ that had a uniform pattern of practice were considered for the study. Critically ill patients who required urgent care and could not be registered by the routine registration process were excluded. The distance from the hospital to the patients' residence was calculated using Google maps and in cases of incomplete addresses, PIN codes were used.

The waiver for informed consent was obtained from the Ethics Committee due to the retrospective nature of the study. The procedures followed were in accordance with the ethical standards of the responsible committee on human experimentation (institutional or regional) and with the Helsinki Declaration of 1964, as revised in 2013. The required data was collected from the hospital quality control records and was categorized and analyzed using SPSS software version 23.

\section{Statistical Analysis}

The power of the study was $80 \%$ and significance level was assessed at 5\% level. Categorical data was represented in frequency and percentage, and difference of all the categorical variables were analyzed by chi-squared test.

\section{Results}

A total of 869 patients visited the clinics in the two specified study periods, out of which 490 and 379 patients were on PCP and PLRP, respectively. They were categorized based on demographic factors, disease-related, and hospital visit-related parameters as shown in - Table 1. Among them, 19 and $81 \%$ patients in PCP and 28 and $72 \%$ patients in PLRP were of ages $\leq 50$ years and $>50$ years, respectively $(p=0.004)$ ( - Fig. 1A). During the PCP, $78 \%$ of patients had solid tumors and $22 \%$ had hematological malignancies, whereas in PLRP, this was 85 and $15 \%$, respectively ( $p=0.006)$ ( - Fig. 1B).

Our hospital encourages patients to avail a prebooking facility that categorizes patients according to the purpose of their booking into chemotherapy, admissions, new registrations, follow-up patients, or special cases and if not prebooked, they will be categorized as walk-in visits. The prebooking facility was utilized by $77 \%$ of patients in PCP and 66\% in PLRP $(p=0.0001)$ ( - Fig. 2A). - Table 1 depicts the patients according to their booking categories and a significant difference was found when we compared the PCP with PLRP ( - Fig. 2B). Specifically, there was a marked reduction in the follow-up patients from 54\% in the PCP to $38 \%$ in PRLP ( $p=0.0001)$. Number of new registrations, inpatient occupancy, and number of patients who took chemotherapy in day care during these periods were not statistically significant (-Fig. 3).

More than $95 \%$ of our patients belong to either the home district of Thrissur or nearby three districts of Ernakulam, Malappuram, or Palakkad. This distribution did not change in the PLRP, even though there were travel restrictions and curbs. The distance from patients' home to hospital during these phases was also calculated ( $\mathbf{-}$ Table $\mathbf{1}$ ) and did not show a statistical difference between the two phases.
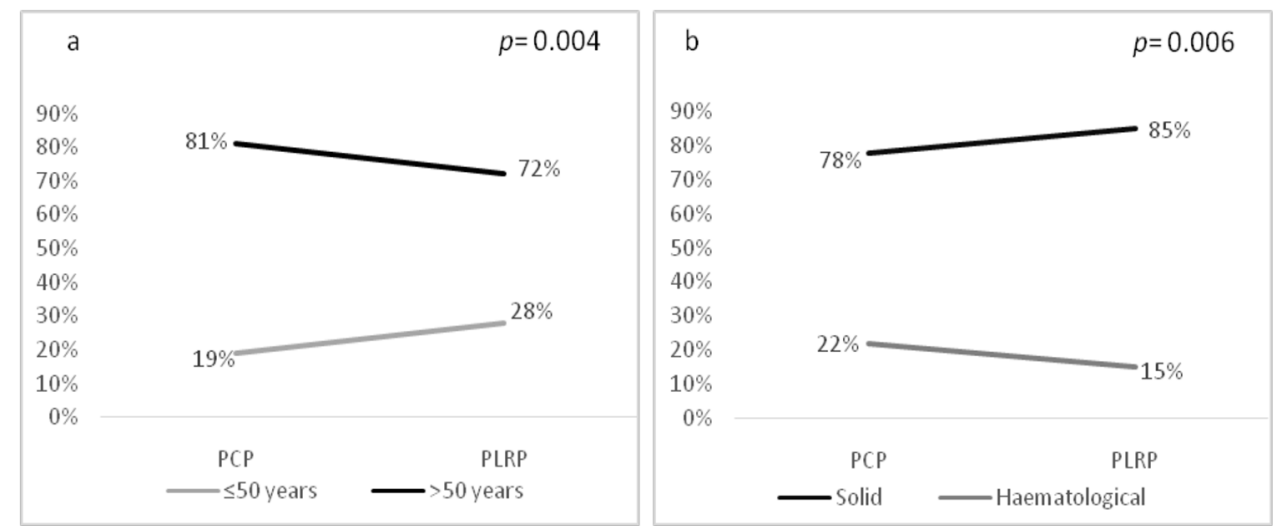

Fig. 1 Distribution of patients with respect to age and type of malignancy. PCP, pre-coronavirus disease phase; PLRP, post lockdown relaxation phase. 
Table 1 Distribution of patients with respect to different factors in PCP and PLRP

\begin{tabular}{|c|c|c|c|}
\hline Patient characteristics & PCP & PLRP & $p$-Value ${ }^{a}$ \\
\hline Age & & & 0.004 \\
\hline$\leq 50 \mathrm{y}$ & $95(19 \%)$ & $105(28 \%)$ & \\
\hline$>50 y$ & $395(81 \%)$ & $274(72 \%)$ & \\
\hline Sex & & & 0.919 \\
\hline Male & $160(33 \%)$ & $254(67 \%)$ & \\
\hline Female & $330(67 \%)$ & $125(33 \%)$ & \\
\hline District & & & 0.818 \\
\hline Thrissur & $347(71 \%)$ & $267(70 \%)$ & \\
\hline Palakkad & $68(13 \%)$ & $50(14 \%)$ & \\
\hline Malappuram & $23(5 \%)$ & $19(5 \%)$ & \\
\hline Ernakulam & $33(7 \%)$ & $32(8 \%)$ & \\
\hline Others & $19(4 \%)$ & $11(3 \%)$ & \\
\hline Distance & & & 0.326 \\
\hline 0-50 km & $365(74 \%)$ & $284(75 \%)$ & \\
\hline $51-100$ km & $102(21 \%)$ & $77(20 \%)$ & \\
\hline $101-500$ km & $23(5 \%)$ & $16(4 \%)$ & \\
\hline$>500 \mathrm{~km}$ & $0(0 \%)$ & $2(1 \%)$ & \\
\hline Type of malignancy & & & 0.006 \\
\hline Solid & $382(78 \%)$ & $323(85 \%)$ & \\
\hline Hematological & $108(22 \%)$ & $56(15 \%)$ & \\
\hline Type of appointment & & & 0.0001 \\
\hline Prebooked & $376(77 \%)$ & $250(66 \%)$ & \\
\hline Not booked & $114(23 \%)$ & $129(34 \%)$ & \\
\hline Purpose of booking & $(n=376)$ & $(n=250)$ & 0.0001 \\
\hline Follow-up & $202(54 \%)$ & $95(38 \%)$ & \\
\hline Chemotherapy & $93(25 \%)$ & $90(36 \%)$ & \\
\hline Admission & $73(19 \%)$ & $56(23 \%)$ & \\
\hline Special booking & $8(2 \%)$ & $9(3 \%)$ & \\
\hline Laboratory services & & & 0.128 \\
\hline From hospital & $53(11 \%)$ & $54(14 \%)$ & \\
\hline Outside hospital & $437(89 \%)$ & $325(86 \%)$ & \\
\hline Day care chemotherapy & 125 & 116 & 0.097 \\
\hline New patients & 31 & 35 & 0.11 \\
\hline IP occupancy & 133 & 118 & 0.198 \\
\hline
\end{tabular}

Abbreviations: IP, inpatient; PCP, pre-coronavirus disease phase; PLRP, post lockdown relaxation phase.

${ }^{a}$ Chi-squared test $p$-value.

\section{Discussion}

On April 15, 2009, in California, two children were diagnosed to have the infamous swine flu. Very soon, with multiple confirmed cases all over the world, the WHO declared it as "A Public Health Emergency of International concern." ${ }^{7,8}$ It took nearly 8 months for vaccines to become widely available, but by then H1N1 was already on the decline after claiming 151,700 to 575,400 lives. ${ }^{9}$ It was nowhere compared with the 1918 Swine flu that is estimated to have killed as many as 50 million people. ${ }^{10}$

Currently, the world is going through the COVID-19 pandemic caused by the severe acute respiratory syndrome coronavirus 2 (SARS-CoV-2). It began as an 


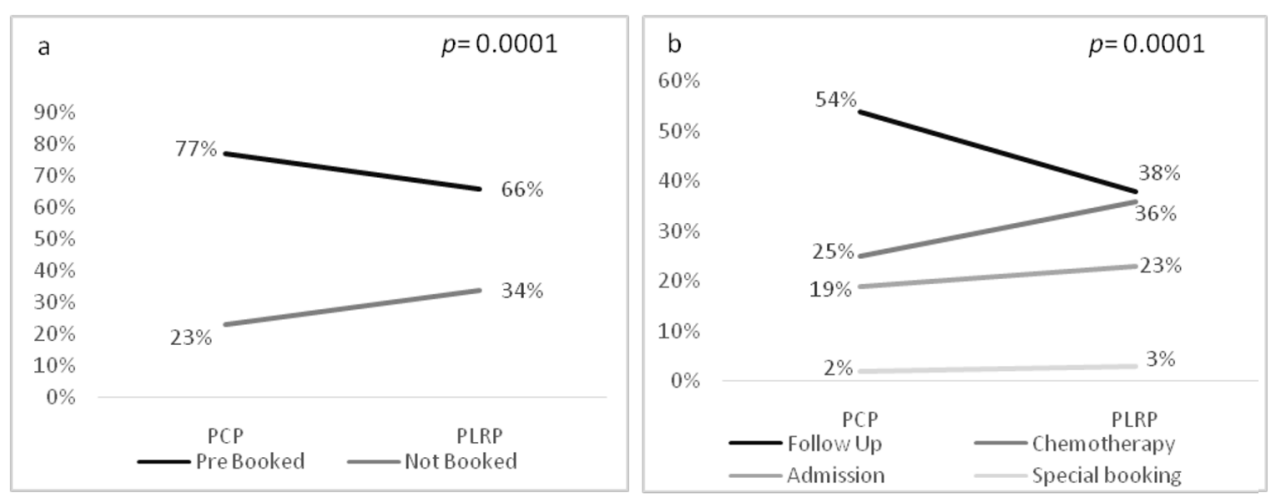

Fig. 2 Distribution of patients with respect to booking categories. PCP, pre-coronavirus disease phase; PLRP, post lockdown relaxation phase.

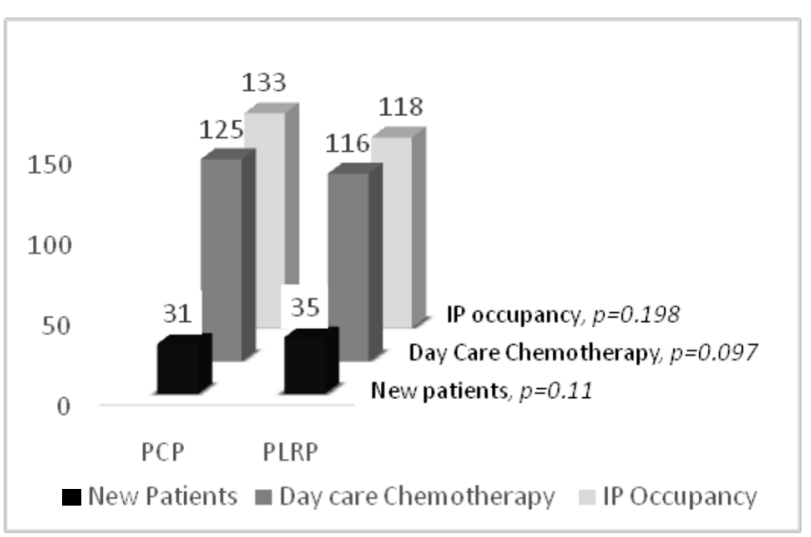

Fig. 3 Distribution of new patients, day care chemotherapy, and IP occupancy. IP, inpatient; PCP, pre-coronavirus disease phase; PLRP, post lockdown relaxation phase.

epidemic in China in the city of Wuhan and gradually found its way around the globe to cause massive death tolls.

China had announced a complete lockdown at Wuhan to contain the virus. People started returning to their natives and one of them from Kerala became the patient " 0 ," the first identified case of COVID-19 in India on January 30, $2020 .{ }^{11}$ After the initial successful containment, nationwide lockdown was imposed from March 25 onward as an attempt to contain the virus. ${ }^{12,13}$ In the midst of this havoc, providing care to the patients suffering from cancer has been very challenging. ${ }^{14}$

Noncommunicable diseases caused $71 \%$ of total deaths in the world ${ }^{15}$ and $63 \%$ of all deaths in India in 2016, in which cancer is one of the leading causes (9\%). ${ }^{16}$ According to GLOBOCAN 2018, there were 18.1 million new cancer cases and 9.6 million cancer deaths in $2018 .{ }^{17}$ Consistent follow-up of patients, regular monitoring and prompt interventions are important in terms of morbidity and mortality, especially in areas like oncology where most patients will be kept on follow-up for years.

This study compares the PCP and PLRP systemic cancer care changes in a tertiary center. The center is one of the oldest standalone cancer centers in Kerala and is now a multidisciplinary hospital of more than a thousand beds treating large number of COVID-19 patients as well.
In a pandemic like this, fear and anxiety of exposure to the virus are expected to hold back patients from going for treatment that potentially could worsen the patient's condition. This is a challenge faced by oncologists' world over. This study is an attempt to see how this challenge has unfolded in the real world and we try to quantify this in a systematic manner.

The total number of patients who visited the hospital in the month of April $(n=379)$ were less when compared with the month of January $(n=490)$. This may be due to the increasing concern of the people about getting exposed to COVID-19 and also the uncertainty of the natural history of the SARS CoV-2 virus infection during this early period. This was a period when the fear of the COVID-19 temporarily ruled over the concerns of cancer. No significant difference was noted in terms of gender, but statistically significant differences were noted with respect to age. The number of people above the age of 50 who visited hospital were significantly less when compared with the younger population ( $p$ $=0.004$ ). This reflected the spreading awareness that elderly patients in particular were more susceptible to adverse clinical outcomes of COVID-19 infection. Even when the lockdown was relaxed, people above 65 years and below 10 years were strictly advised to stay indoors except for essential travels. ${ }^{18}$ That is a probable explanation for the elderly avoiding hospital visits. At this time, though telemedicine was not completely functional, many patients resorted to direct phone calls to the hospital for advices and delayed physical appointments. This approach was mostly seen in patients who were under regular follow-up or oral maintenance therapies.

The majority of our patients were from within the state itself. Approximately, $30 \%$ of the patients were from districts other than Thrissur, (the home district of the hospital), both in PCP and PLRP. It was also noted that in both the periods of study, around $25 \%$ of the patients had to travel a distance more than $50 \mathrm{~km}$ to reach the hospital. Interstate and interdistrict travel restrictions could have resulted in a drop in the patient number, but our study did not reveal a statistically significant difference in number of patients regarding district or distance from hospital. Perhaps, in the initial phase of the lockdown, the disease was well contained in Kerala. During these days, there were travel restrictions still in 
place but with strict instructions for traffic authorities to permit essential and hospital travels. This "privilege" was used effectively by cancer patients irrespective of the distance from their home to the hospital. This perhaps indicates that patients considered cancer treatment seriously despite COVID-19 scare building up during this period.

Hematologic malignancies appear to have a greater risk of SARS-CoV-2 infection and severe disease due to myelosuppression..$^{19}$ In our practice, there was significant reduction in the number of patients with hematological malignancies coming to clinics after the lockdown was relaxed $(p=0.006)$. Practical suggestions and consensus statements advise the use of telemedicine, blood investigations performed at nearby laboratories, hospital visits at extended intervals for follow-up (every 3 months), and use of oral drugs for the management of patients with hematologic malignancies during the COVID-19 pandemic. ${ }^{19}$ Even though most of these measures were followed in our hospital, we could not find a real reason for this shift. Studies involving larger number of patients would be needed to ascertain if this trend was real.

Many patients had to cancel their previously booked hospital visits during the month of March and early April due to the lockdown. Hence, there was a significant increase in the number of patients who came without prebooked appointments after the initial phase of the lockdown $(p=0.0001)$. The importance of prebooking is that this would help in reducing the time spent in the hospital premises. As described earlier, the gradual increase in public awareness of COVID-19 and increasing concern about being exposed to the virus would have been a reason for significant reduction in the number of patients who came for follow-up visits in April as compared with visits for other purposes like chemotherapy or admis$\operatorname{sion}(p=0.0001)$.

New patient registrations, inpatient occupancy, and day care chemotherapy were not significantly affected during this period of the pandemic ( - Fig.3) that points to the fact that patients are well aware about the need and importance of timely cancer care even during the COVID-19 pandemic. This constitutes the active systemic cancer care patients' group. The COVID-19 pandemic is slowly categorizing cancer care into "essential" and "nonessential" domains. ${ }^{20}$ Our finding of a continued active systemic treatment and reduction in follow-up patients reflects an early deviation in our practice also in these lines.

It is interesting to see that even though travel restrictions were not completely relaxed in the PLRP, still the proportion of patients coming from distant places did not vary significantly.

In terms of a reduction in the proportion of follow-up patients, the real impact of this on cancer care can be ascertained only over a longer period of follow-up. This impact would be mainly in terms of missing an opportunity to identify an early relapse or identifying long-term treatment complications. Our numbers seem to be small to significantly identify the impact of this difference. Larger registry-based studies would be required for this and would be really meaningful to prepare for future similar situations.
During the pandemic, there were multiple reports regarding the number of patients coming to hospitals for non-COVID-19 reasons becoming very lean. But our data suggests that this might not be the case for cancer treatment when the pandemic is under control. For yet to be identified reasons, we witnessed a reduction in hematological cancer patients coming to clinic in our practice,

Our results contradict the results of an earlier study conducted in United States, which reported a $40 \%$ decline in weekly cancer incidence during the pandemic time. ${ }^{21}$ This disparity can be explained by the fact that our study was conducted during the post lockdown phase, during which travel restrictions had been lifted, ensuring smooth inflow of new patients. Also, since the pandemic was well under control in the region of study during the study period, the results cannot be taken as a generalized cross-section of the severely COVID-19 affected regions. On April 30, 2020, the cumulative number of COVID-19 cases in Kerala (with a population of around 36 million) were still 498 cases with only four deaths reported. ${ }^{22}$ This could strengthen the pandemic management philosophy of "flattening the curve" and thereby avoiding overcrowding of hospitals. This was apparently achieved in Kerala by strict implementation of lockdown and post lockdown relaxation measures. This might have empowered the patients to continue their cancer treatment. Potentially this could have reduced an indirect increase in cancer specific mortality that would have otherwise been high, in a full-blown pandemic.

The fact that inpatient occupancy and day care chemotherapy were not significantly affected ( - Fig. 3 ) points out that patients are well aware about the need and importance of timely cancer care even during the COVID-19 pandemic. A study from Turkey has reported a $10 \%$ increase in admissions for cancer-related treatments and 15\% increase in hospitalization for chemotherapy. ${ }^{23}$

Our study throws light to the fact that if the pandemic does not overcrowd the hospital, there is a good possibility that treatment of other diseases won't be affected. This should be considered significantly while managing similar situations in the future. The impact of COVID-19 on cancer care is yet to unfold fully. The early impact might be what is demonstrated here partly. The mid-term and long-term effects are yet to be known and the way the pandemic has treated the society, these effects are bound to have so many surprises. Also, the long-term legacy that COVID-19 would leave on cancer is yet to be known, though experts predict that a new normal is going to come..$^{20,24}$

The limitation of our data are the short time period of the study and the small numbers of patients. Ideally the comparison should have happened between corresponding periods of 2 years but one of the units whose data has been taken for this study was not in established during the corresponding period of the previous year. Also, we haven't looked into cancer related mortality in these periods. How COVID-19 has impacted other cancer care modalities like radiation oncology and surgery would also be interesting to look into. Moreover, since vaccinations for COVID-19 are now available, 
further studies focusing the cancer care post vaccination will also prove of prime importance.

\section{Conclusion}

Overall COVID-19 has not affected systemic cancer care in the immediate PLRP when the outbreak had not reached its peak but elderly patients and others who were up for follow-up had hesitations to come to hospital during this period. Patients considered cancer treatment importantly during COVID-19 outbreak if the outbreak was under control.

\section{Contributors' Details}

Anakha Pattiyeil was involved in conceptualization, designing, definition of intellectual content, literature search, clinical studies, data acquisition, data analysis, statistical analysis, manuscript preparation, manuscript editing, manuscript review; Febin Antony was involved in conceptualization, designing, definition of intellectual content, literature search, clinical studies, data analysis, statistical analysis, manuscript preparation, manuscript editing, and manuscript review; Sunu L Cyriac was involved in conceptualization, designing, definition of intellectual content, clinical studies, manuscript preparation, manuscript editing, and manuscript review; Anilkumar Jose was involved in conceptualization, designing, and definition of intellectual content; Jini MP was involved in definition of intellectual content, data analysis, and statistical analysis. All the authors have given guarantee for this manuscript.

\section{Source of Funding}

No funding received for this study.

\section{Conflict of Interest}

All authors report no conflict of interests.

\section{References}

1 Grennan D. What is a pandemic? JAMA 2019;321(9):910

2 who.int.[internet].WHODirector-General's opening remarks at the media briefing on COVID-19-11 March2020.Availablefrom: https://www.who.int/director-general/speeches/detail/whodirector-general-s-opening-remarks-at-the-media-briefingon-covid-19-11-march-2020. Accessed April 26, 2021

3 who.int. [internet]. WHO Coronavirus Disease (COVID-19) Dashboard | WHO Coronavirus Disease (COVID-19) Dashboard. Available from: https://covid19.who.int/.Accessed April 26, 2021

4 Liang W, Guan W, Chen R, et al. Cancer patients in SARS-CoV-2 infection: a nationwide analysis in China. Lancet Oncol 2020;21(3):335-337

5 newindianexpress.com. [internet]. India lockdown: States, airlines, railways consider steps to relax curbs in phases from April 15-The New Indian Express. Available from: https:// www.newindianexpress.com/nation/2020/apr/04/indialockdown-states-airlines-railways-consider-steps-to-relax-curbs-in-phases-from-april-15-2125871.html. Accessed April 26, 2021

6 indianexpress.com. [internet]. Coronavirus India Updates April 15: Cases cross 11,000 mark; Health Ministry identifies 170 hotspots | coronavirus outbreak News-The Indian Express.
Available from: https://indianexpress.com/article/coronavirus/coronavirus-india-latest-updates-april-15-mha-guidelines-6363234/. Accessed April 26, 2021

7 Smith GJ, Vijaykrishna D, Bahl J, et al. Origins and evolutionary genomics of the 2009 swine-origin H1N1 influenza A epidemic. Nature 2009;459(7250):1122-1125

8 Burkardt HJ. Pandemic H1N1 2009 ('swine flu'): diagnostic and other challenges. Expert Rev Mol Diagn 2011;11(1):35-40

9 Doshi P. The 2009 influenza pandemic. Lancet Infect Dis 2013;13(3):193

10 Nelson MI, Worobey M. Origins of the 1918 pandemic: revisiting the Swine "Mixing Vessel" hypothesis. Am J Epidemiol 2018;187(12):2498-2502

11 Mathur P, Sathishkumar K, Chaturvedi M, et al. ICMRNCDIR-NCRP Investigator Group. Cancer Statistics, 2020: report from National Cancer Registry Programme, India. JCO Glob Oncol 2020;6:1063-1075

12 timesofindia.indiatimes.com. [internet]. Kerala Lockdown: Kerala to go under lockdown till March 31|Thiruvananthapuram News - Times of India. Available from: https://timesofindia. indiatimes.com/city/thiruvananthapuram/kerala-to-go-under-lockdown-till-march-31/articleshow/74778886.cms. Accessed April 26, 2021

13 thehindu.com. [internet]. PM Modi announces 21-day lockdown as COVID-19 toll touches 12 - The Hindu. Available from: https://www.thehindu.com/news/national/pm-announces21-day-lockdown-as-covid-19-toll-touches-10/article31156691.ece. Accessed April 26, 2021

14 Gosain R, Abdou Y, Singh A, Rana N, Puzanov I, Ernstoff MS. COVID-19 and cancer: a comprehensive review. Curr Oncol Rep 2020;22(5):53

15 who.int. [internet]. Noncommunicable diseases. Available from: https://www.who.int/news-room/fact-sheets/detail/ noncommunicable-diseases. Accessed April 26, 2021

16 who.int. [internet]. World Health Organization Noncommunicable Diseases (NCD) Country Profiles, 2018. Available from: https://www.who.int/nmh/countries/ind_ en.pdf?ua=1. Accessed April 26, 2021

17 Bray F, Ferlay J, Soerjomataram I, Siegel RL, Torre LA, Jemal A. Global cancer statistics 2018: GLOBOCAN estimates of incidence and mortality worldwide for 36 cancers in 185 countries. CA Cancer J Clin 2018;68(6):394-424

18 Perrotta F, Corbi G, Mazzeo G, et al. COVID-19 and the elderly: insights into pathogenesis and clinical decision-making. Aging Clin Exp Res 2020;32(8):1599-1608

19 Isidori A, de Leval L, Gergis U, Musto P, Porcu P. Management of patients with hematologic malignancies during the COVID-19 pandemic: practical considerations and lessons to be learned. Front Oncol 2020;10:1439

20 Broom A, Kenny K, Page A, et al. The paradoxical effects of COVID-19 on cancer care: current context and potential lasting impacts. Clin Cancer Res 2020;26(22):5809-5813

21 Kaufman HW, Chen Z, Niles J, Fesko Y. Changes in the number of us patients with newly identified cancer before and during the coronavirus disease 2019 (COVID-19) pandemic. JAMA Netw Open 2020;3(8):e2017267

22 covid19india.org. [internet]. Coronavirus Outbreak in India covid19india.org. Available from: https://www.covid19india. org/. Accessed April 26, 2021

23 Guven DC, Aktas BY, Aksun MS, et al. COVID-19 pandemic: changes in cancer admissions. BMJ Support Palliat Care 2020;:bmjspcare-2020-002468

24 Luker GD, Boettcher AN. Transitioning to a new normal after COVID-19: preparing to get back on track for cancer imaging. Radiol Imaging Cancer 2020;2(3):e204011 